\title{
PENGARUH DENTAL BRAILLE EDUCATION (DBE) TERHADAP ORAL HYGIENE PADA ANAK TUNANETRA
}

\author{
Muhammad Fiqih Sabilillah ${ }^{\bowtie 1}$, Rieza Zulfahmi Taftazani ${ }^{2}$, \\ Yayah Sopianah $^{3}$, Diyah Fatmasari ${ }^{4}$
}

\begin{abstract}
ABSTRAK
Anak tunanetra mempunyai keadaan rongga mulut yang buruk. Buruknya keadaan ini disebabkan karena tindakan menyikat gigi yang tidak diawasi, faktor-faktor lain seperti teknik menyikat gigi, keterampilan motorik dan bantuan pendampingan yang masih diabaikan. Selain itu kurangnya visualisasi untuk memahami dan menguasai teknik praktik kebersihan gigi dan mulut. Penelitian ini bertujuan untuk menganalisis pengaruh Dental Braille Education (DBE) terhadap Oral Hygiene pada anak tunanetra.

Penelitian pre experimental dengan rancangan the group pre-posttest design, selanjutnya dilakukan pemeriksaan Plak Indeks sebelum intervensi. Intervensi yang diberikan pada sampel yaitu berupa DBE kemudian di evaluasi pada hari ke 21. Keluaran atau outcome pada penelitian ini berupa penilaian derajat oral hygiene menggunakan Plak Indeks dan DBE berbentuk booklet. Sampel penelitian ini menggunakan metode purposive sampling. Analisis data menggunakan statistik deskriptif dalam bentuk tabel (boxplot atau diagram), kemudian analisis bivariat non parametrik menggunakan wilcoxon untuk mengetahui perubahan oral hygiene pada hasil pretest ke hasil posttest. Analisis data dalam penelitian ini menggunakan program komputer dengan pengujian hipotesis berdasarkan taraf signifikan a $<0,05$ dengan tingkat kepercayaan $95 \%$.

Hasil analisis selisih perubahan oral hygiene dari posttest ke pretest menunjukkan ada perubahan yang signifikan, ditunjukkan dengan $Z=-3,126$ dan $p=0,002(p>0,005)$. Dapat disimpulkan bahwa hipotesis yang menyatakan ada pengaruh DBE terhadap oral hygiene pada anak tunanetra dapat diterima karena pada dasarnya keadaan intelegensi anak tunanetra itu tidak berbeda dengan anak normal, oleh karena itu dibutuhkan pendekatan dan komunikasi yang baik dalam menanganinya.
\end{abstract}

Kata kunci: Dental Braille Education (DBE), Oral Hygiene, Anak Tunanetra

\begin{abstract}
Blind children has poor oral hygiene. Such condition due to tooth brushing is not monitored, other factors such as brushing technique, motor skills and mentoring assistance are still negligible. Besides the lack of visualization to understand and master the techniques of oral hygiene practices. This study aimed to analyze the influence of Braille Dental Education (DBE) against Oral Hygiene in blind children.

Pre-experimental research design with the group pre-posttest design, further examination Plaque Index before the intervention. Intervention is given on a sample in the form of DBE and then evaluated at day 21. The outputs or outcomes in this study of assessment of the degree oral hygiene using the Plaque Index and DBEshaped booklet. The research sample using purposive sampling method. Data analysis using descriptive statistics in the form of tables (boxplot or diagram), then the bivariate analysis using the non-parametric Wilcoxon to determine changes in oral hygiene on the results of the pretest to posttest results. Analysis of the data in this study using a computer program to test the hypothesis based on a significance level of $<0.05$ with $95 \%$ confidence level.

The results of the analysis of the difference in oral hygiene change from pretest to posttest showed no significant changes, indicated by $Z=-3.126$ and $p=0.002(p>0.005)$. It can be concluded that the hypothesis that there was an effect on oral hygiene DBE in blind children is acceptable because it is essentially a state intelligence of blind children is not different from normal children, and therefore requires an approach and good communication in handling it.
\end{abstract}

Key words : Dental Braille Education (DBE), Oral Hygiene, Children with Visual Impairment

\footnotetext{
$\overline{1,2,3)}$ Dosen Jurusan Keperawatan Gigi Poltekkes Kemenkes Tasikmalaya

4) Dosen Jurusan Keperawatan Gigi Poltekkes Kemenkes Semarang
}

: sabilillah.fiqih@gmail.com 


\section{PENDAHULUAN}

Pembangunan kesehatan bertujuan untuk meningkatkan kesadaran, kemauan dan kemampuan hidup sehat bagi setiap orang agar terwujud derajat kesehatan masyarakat yang setinggi-tingginya, sebagai investasi bagi pembangunan sumber daya manusia yang produktif secara sosial dan ekonomi. Anak berkebutuhan khusus termasuk penyandang cacat merupakan salah satu sumber daya manusia bangsa Indonesia yang kualitasnya harus ditingkatkan agar dapat berperan, tidak hanya sebagai obyek pembangunan tetapi juga sebagai subyek pembangunan (Kemenkes, 2010).

Anak berkebutuhan khusus adalah anak yang mengalami keterbatasan atau keluarbiasaan, baik fisik, mental-intelektual, sosial maupun emosional, yang berpengaruh secara signifikan dalam proses pertumbuhan atau perkembangannya dibandingkan dengan anak-anak lain yang seusia dengannya (Kemen-PPPA, 2013). World Health Organization (WHO) memperkirakan jumlah anak berkebutuhan khusus di Indonesia sekitar 7-10\% dari total jumlah anak. Menurut data Survei Sosial Ekonomi Nasional (SUSENAS) tahun 2003, di Indonesia terdapat 679.048 anak usia sekolah berkebutuhan khusus atau $21,42 \%$ dari seluruh jumlah anak berkebutuhan khusus (Kemenkes, 2010).

Berdasarkan Susenas Triwulan 1 Maret 2011, jumlah anak Indonesia sebanyak 82.980.000, dari populasi tersebut, 9.957.600 anak adalah anak berkebutuhan khusus dalam kategori penyandang disabilitas. Jumlah anak dengan kecerdasan istimewa dan berbakat istimewa adalah sebesar 2,2\% dari populasi anak usia sekolah (4-18 tahun) atau sekitar 1.185.560 anak (Kemen-PPPA, 2013). Anak berkebutuhan khusus perlu dikenali dan diidentifikasi dari kelompok anak pada umumnya, karena mereka memerlukan pelayanan yang bersifat khusus, seperti pelayanan medik, pendidikan khusus maupun latihan-latihan tertentu yang bertujuan untuk mengurangi keterbatasan dan ketergantungan akibat kelainan yang diderita, serta menumbuhkan kemandirian hidup dalam bermasyarakat (Kemenkes, 2010).

Salah satu anak berkebutuhan khusus yang memerlukan pelayanan yang bersifat khusus adalah anak tunanetra. Buruknya keadaan rongga mulut tunanetra disebabkan karena tindakan menyikat gigi yang tidak diawasi, faktor-faktor lain seperti teknik menyikat gigi, keterampilan motorik dan bantuan pendampingan yang masih diabaikan (Reddy et al., 2014). Selain itu kurangnya visualisasi untuk memahami dan menguasai teknik praktik kebersihan gigi dan mulut (Singh et al., 2014).

Kebersihan gigi dan mulut yang buruk disebabkan oleh adanya debris dan plak yang dapat menyebabkan timbulnya gingivitis dan paparan jangka panjang plak dapat menyebabkan hilangnya perlekatan periodontal. Paparan jangka panjang plak juga dapat menyebabkan demineralisasi dan perusakan gigi sehingga terjadi karies (Broadbent et al., 2011). Kebersihan gigi dan mulut yang buruk juga bisa menyebabkan adanya plak dan kalkulus. Plak dan akumulasi bakteri berkontribusi terhadap memburuknya kesehatan mulut dan menyebabkan penyakit periodontal (Zeng et al., 2015).

Penelitian di India Prevalence of dental caries and oral hygiene status among Blind School Children and Normal children menunjukkan prevalensi kebersihan gigi dan mulut tunanetra adalah (40\%) termasuk dalam kategori buruk (Ravishankar et al., 2013). Sementara di Indonesia sebanyak (50\%) tunanetra memiliki tingkat kebersihan gigi dan mulut rata-rata 2,3 termasuk kategori sedang (Agnintia et al., 2013). Kebersihan gigi dan mulut yang buruk pada tunanetra disebabkan 3 hal yaitu, makanan kariogenik, bentuk posisi gigi dan kurangnya pengetahuan tentang kesehatan gigi dan mulut pada tunanetra yang dikarenakan kurangnya edukasi tentang cara menjaga kebersihan gigi dan mulut (Sheehy et al.,2004). 
Metode-metode untuk meningkatkan kebersihan gigi dan mulut pada anak tunanetra diantaranya yaitu pendidikan penyikatan gigi dengan menggunakan model rahang dan metode pendampingan pada saat menyikat gigi (Putri et al., 2014). Quality self care and home care solusi kesehatan gigi dan mulut anak tunanetra (Agnintia et al., 2013). Efektivitas berbagai macam cara memegang sikat gigi untuk menghilangkan plak gigi pada anak-anak tunanetra (Raiyani et al., 2014). Efektivitas program pendidikan kesehatan gigi dengan dan tanpa melibatkan keterampilan kebersihan mulut pada anak tunanetra (Kumar et al., 2013). Tunanetra belajar Metode menyikat gigi dengan menggunakan teknik taktil (Kadkhoda et al., 2014).

Salah satu metode mengajar yang dianggap sangat tepat dan cocok untuk mengajarkan materi menyikat gigi adalah Dental Braille Education (DBE). Dental Braille Education (DBE) merupakan suatu proses belajar dalam bidang kesehatan gigi dan mulut yang dikhususkan bagi tunanetra atau seseorang disabilitas penglihatan menggunakan media huruf braille sehingga diharapkan dapat mewujudkan derajat kesehatan gigi dan mulut yang optimal serta memiliki kemandirian dalam menjaga kesehatan giginya.

Penelitian ini bertujuan untuk menganalisis pengaruh Dental Braille Education (DBE) terhadap Oral Hygiene pada anak tunanetra.

\section{METODE PENELITIAN}

Penelitian pre experimental dengan rancangan the group pre-posttest design, selanjutnya dilakukan pemeriksaan Plak Indeks sebelum intervensi. Intervensi yang diberikan pada sampel yaitu berupa Dental Braille Education (DBE) kemudian di evaluasi pada hari ke 21. Penelitian ini dilaksanakan selama 21 hari sesuai dengan teori Foster dalam Maher dkk (2014), yang menyatakan bahwa perubahan perilaku kesehatan dapat diukur setelah 21 hari. Metode pengambilan sampel dalam penelitian ini menggunakan metode purposive sampling (Lawrence, 2006). Analisis data disajikan dalam bentuk tabel dan diolah sebagai berikut :

Tabel 1. Analisis Hasil Penelitian

\begin{tabular}{cll}
\hline No & \multicolumn{1}{c}{ Analisis } & \multicolumn{1}{c}{ Tujuan } \\
\hline 1 & Non Parametrik & Untuk mengetahui perubahan \\
menggunakan & oral hygiene pada hasil pretest \\
& Wilcoxon & ke hasil posttest \\
\hline
\end{tabular}

\section{HASIL DAN PEMBAHASAN}

1. Karakteristik Responden

Penelitian ini dilaksanakan di SLB Negeri Tamansari Kota Tasikmalaya. Responden pada penelitian ini adalah anak tunanetra yang ada di SLB Negeri Tamansari Kota Tasikmalaya yang berjumlah 12 anak. Karakteristik responden penelitian berdasarkan jenis kelamin dapat dilihat pada tabel dibawah ini :

Tabel 2. Karakteristik Responden Penelitian Berdasarkan Jenis Kelamin

\begin{tabular}{clcc}
\hline No & Jenis Kelamin & $\mathrm{n}$ & $\%$ \\
\hline 1 & Laki-Laki & 4 & 33,3 \\
2 & Perempuan & 8 & 66,7 \\
& Total & 12 & 100 \\
\hline
\end{tabular}

Tabel 2 karakteristik responden penelitian berdasarkan jenis kelamin menunjukkan bahwa sebanyak 4 anak $(33,3 \%)$ berjenis kelamin laki-laki dan 8 anak $(66,7 \%)$ berjenis kelamin perempuan. Karakteristik responden penelitian berdasarkan jenis kelamin mayoritas berjenis kelamin perempuan. Selanjutnya pada karakteristik responden penelitian berdasarkan sekolah dapat dilihat pada tabel dibawah ini :

Tabel 3. Karakteristik Responden Penelitian Berdasarkan Sekolah

\begin{tabular}{cccc}
\hline No & Sekolah & $\mathrm{n}$ & $\%$ \\
\hline 1 & SDLB & 6 & 50 \\
2 & SMALB & 6 & 50 \\
& Total & 12 & 100 \\
\hline
\end{tabular}


Tabel 3 karakteristik responden penelitian berdasarkan sekolah menunjukkan bahwa sebanyak 6 anak (50\%) di SDLB dan sebanyak 6 anak (50\%) di SMALB.

\section{Analisis Univariat}

Analisis univariat dengan deskriptif pada oral hygiene dilakukan sebelum (pretest) dan sesudah (post-test) intervensi. Oral hygiene diukur dengan menggunakan Indeks Plak. Indeks plak dicantumkan kedalam formulir, dengan tujuan untuk mencatat hasil pemeriksaan oral hygiene responden.

Penilaiannya dengan menilai seluruh gigi pada bagian permukaan fasial dan lingual setelah pemberian disclosing solution. Skor plak perorangan diperoleh dari jumlah total nilai yang diperoleh dibagi jumlah permukaan yang diperiksa. Hasil analisis univariat dengan deskriptif pada oral hygiene sebelum (pre-test) dan sesudah (post-test) intervensi dapat dilihat pada tabel dibawah ini :

Tabel 4. Analisis Univariat dengan Deskriptif pada Oral Hygiene Sebelum (pre-test) dan Sesudah (post-test) Intervensi

\begin{tabular}{ccccccc}
\hline No & \multicolumn{1}{c}{ Kriteria } & n & Mean & SD & Min & Max \\
\hline 1 & $\begin{array}{l}\text { Kriteria Plak } \\
\text { Indeks (Pretest) }\end{array}$ & 12 & 3,75 & 0,452 & 3 & 4 \\
2 & $\begin{array}{l}\text { Kriteria Plak } \\
\text { Indeks (Posttest) }\end{array}$ & 12 & 2,08 & 0,669 & 1 & 3 \\
\hline
\end{tabular}

Tabel 4 analisis univariat dengan deskriptif pada oral hygiene sebelum intervensi (pre-test) menunjukkan bahwa sebanyak 12 anak didapatkan kriteria terendah adalah 3 (sedang) dan kriteria tertinggi adalah 4 (buruk). Rata-rata (mean) kriteria yang didapatkan dari responden adalah 3,75 dengan standar deviation 0,452. Selanjutnya setelah intervensi (posttest) menunjukkan bahwa sebanyak 12 anak didapatkan kriteria terendah adalah 1 (sangat baik) dan kriteria tertinggi adalah 3 (sedang). Rata-rata (mean) kriteria yang didapatkan dari responden adalah 2,08 dengan standar deviation 0,669. Distribusi hasil pengukuran oral hygiene sebelum intervensi (pre-test) dapat dilihat pada tabel dibawah ini:
Tabel 5. Distribusi Hasil Pengukuran Oral Hygiene Sebelum Intervensi (pre-test)

\begin{tabular}{ccccc}
\hline No & Kriteria & Skor & $\mathrm{n}$ & $\%$ \\
\hline 1 & Sedang & $1,8-3,4$ & 3 & 25 \\
2 & Buruk & $3,5-5,0$ & 9 & 75 \\
\multicolumn{2}{c}{ Total } & & 12 & 100 \\
\hline
\end{tabular}

Tabel 5 distribusi hasil pengukuran oral hygiene sebelum intervensi (pre-test) menunjukkan bahwa sebanyak 3 anak $(25 \%)$ berkriteria sedang dan sebanyak 9 anak (75\%) berkriteria buruk. Selanjutnya distribusi hasil pengukuran oral hygiene setelah intervensi (pre-test) dapat dilihat pada tabel dibawah ini :

Tabel 6. Distribusi Hasil Pengukuran Oral Hygiene Setelah Intervensi (pre-test)

\begin{tabular}{|c|c|c|c|c|}
\hline No & Kriteria & Skor & $\mathrm{n}$ & $\%$ \\
\hline 1 & Sangat Baik & 0 & 2 & 16,7 \\
\hline 2 & Baik & $0,1-1,7$ & 7 & 58,3 \\
\hline 3 & Sedang & $1,8-3,4$ & 3 & 25 \\
\hline
\end{tabular}

Tabel 6 distribusi hasil pengukuran oral hygiene setelah intervensi (pre-test) menunjukkan bahwa sebanyak 2 anak $(16,7 \%)$ berkriteria sangat baik dan sebanyak 7 anak $(58,3 \%)$ berkriteria baik serta sebanyak 3 anak (25\%) berkriteria sedang.

\section{Pengujian Prasyarat Analisis}

Pengujian prasyarat analisis dilakukan sebelum analisis data. Uji prasyarat analisis menggunakan uji normalitas pada variabel oral hygiene dengan Shapiro-Wilk karena jumlah sampel kurang dari 50. Hasil analisis uji normalitas (Shapiro-Wilk) sebaran data (variabel) dapat dilihat pada tabel dibawah ini :

Tabel 7. Hasil Analisis Uji Normalitas (Shapiro-Wilk) Sebaran Data (Variabel)

\begin{tabular}{|c|c|c|c|c|}
\hline \multirow{2}{*}{ No } & \multirow{2}{*}{$\begin{array}{c}\text { Distribusi Data } \\
\text { (Variabel) }\end{array}$} & \multicolumn{2}{|c|}{ Shapiro-Wilk } & \multirow{2}{*}{ Kesimpulan } \\
\hline & & Statistik & p (Sig) & \\
\hline 1 & Oral hygiene & 0,552 & 0,000 & $\begin{array}{l}\text { Tidak } \\
\text { Normal }\end{array}$ \\
\hline
\end{tabular}

Tabel 7 hasil analisis uji normalitas (shapiro-wilk) sebaran data variabel oral hygiene menunjukkan bahwa signifikan pada 
taraf signifikansi 5\% (p<0,05), hal ini berarti bahwa data penelitian ini terdistribusi (sebaran) tidak normal. Oleh karena itu, dilanjutkan dengan menggunakan uji statistik non parametrik.

\section{Analisis Bivariat}

Analisis bivariat bertujuan untuk menguji hipotesis. Hipotesis tersebut akan diuji dengan menggunakan uji statistik non parametrik wilcoxon untuk mengetahui perubahan oral hygiene pada hasil pretest ke hasil posttest. Analisis bivariat dapat dilihat pada tabel dibawah ini :

Tabel 8. Hasil Analisis Selisih Perubahan Oral Hygiene pada Hasil pretest ke Hasil posttest

\begin{tabular}{lcc}
\hline \multirow{2}{*}{ Variabel } & \multicolumn{2}{c}{ Wilcoxon } \\
\cline { 2 - 3 } & $\mathrm{Z}$ & $\mathrm{p}$ \\
\hline $\begin{array}{l}\text { Oral hygiene } \\
\text { posttest ke pretest }\end{array}$ & $-3,126$ & 0,002 \\
\hline
\end{tabular}

Tabel 8 hasil analisis selisih perubahan oral hygiene dari posttest ke pretest menunjukkan ada perubahan yang signifikan, hal ini ditunjukkan dengan $\mathrm{Z}=$ 3,126 dan $p=0,002(p>0,05)$.

Penelitian ini dilakukan pada anak tunanetra. Tunanetra adalah istilah umum yang digunakan pada seseorang yang mengalami gangguan atau hambatan dalam indera penglihatan. Alat bantu yang digunakan untuk mobilitas bagi tunanetra adalah tongkat khusus dengan warna putih bergaris merah horizontal. Akibat hilang atau berkurangnya fungsi indera penglihatan maka tunanetra berusaha memaksimalkan fungsi indera perabaan, penciuman, pendengaran dan lain sebagainya, sehingga tidak sedikit penyandang tunanetra yang memiliki kemampuan luar biasa di bidang musik atau ilmu pengetahuan. Tunanetra merupakan seseorang yang mengalami gangguan daya penglihatan berupa kebutaan menyeluruh (total) atau sebagian (low vision).

Patokan yang digunakan dalam menentukan seorang anak termasuk tunanetra atau tidak adalah berdasarkan tingkat ketajaman penglihatannya. Penyebab tunanetra dipengaruhi oleh beberapa faktor, diantaranya adalah pre-natal dan post-natal. Pre-natal merupakan faktor ketunanetraan yang terjadi pada masa pre-natal dan sangat erat hubungannya dengan masalah keturunan serta pertumbuhan seorang anak dalam kandungan sedangkan post-natal merupakan faktor penyebab ketunanetraan yang terjadi pada masa post-natal, hal ini dapat terjadi sejak atau setelah bayi lahir. Ketunanetraan pada masa post-natal disebabkan oleh ibu hamil yang menderita penyakit gonorrhoe, trachoma dan akibat kecelakaan.

$$
\text { Berdasarkan hasil analisis }
$$

karakteristik responden penelitian berdasarkan jenis kelamin yang diberi intervensi berupa Dental Braille Education $(D B E)$, didapatkan 4 anak (33\%) berjenis kelamin laki-laki dan 8 anak $(66,7 \%)$ berjenis kelamin perempuan sedangkan karakteristik responden penelitian sekolah, didapatkan 6 anak (50\%) di SDLB dan 6 anak (50\%) di SMALB. Hal ini menunjukkan bahwa sebaran data yang ada cukup berimbang.

Analisis univariat dengan deskriptif pada oral hygiene sebelum (pretest) intervensi menunjukkan bahwa sebanyak 12 anak didapatkan kriteria terendah adalah 3 (sedang) dan kriteria tertinggi adalah 4 (buruk). Rata-rata (mean) kriteria yang didapatkan dari responden adalah 3,75 dengan standar deviation 0,452 sedangkan distribusi hasil pengukuran oral hygiene sebelum intervensi didapatkan sebanyak 3 anak $(25 \%)$ berkriteria sedang dan sebanyak 9 anak $(75 \%)$ berkriteria buruk. Hal ini dapat diartikan masih minimnya informasi tentang perilaku pemeliharaan kesehatan gigi dan mulut yang didapatkan responden dank arena pada saat pretest peneliti belum menyampaikan pengajaran cara pemeliharaan kesehatan gigi dan mulut.

Analisis univariat dengan deskriptif pada oral hygiene setelah (posttest) intervensi menunjukkan bahwa sebanyak 12 anak didapatkan kriteria terendah adalah 1 (sangat baik) dan kriteria tertinggi adalah 3 
(sedang). Rata-rata (mean) kriteria yang didapatkan dari responden adalah 2,08 dengan standar deviation 0,669 sedangkan distribusi hasil pengukuran oral hygiene sebelum intervensi didapatkan sebanyak 2 anak $(16,7 \%)$ berkriteria sangat baik, 7 anak $(58,3 \%)$ berkriteria baik dan 3 anak $(25 \%)$ berkriteria sedang. Hal ini disebabkan oleh peneliti telah menyampaikan pengajaran cara cara pemeliharaan kesehatan gigi dan mulut berupa Dental Braille Education (DBE) sehingga dapat menarik perhatian pada waktu mengajarkan dan dapat memusatkan perhatian pada saat penyajian serta memfokuskan penjelaskan pada materi yang perlu penekanan.

Setelah dilakukan pengujian prasyarat analisis menggunakan uji shapirowilk dan didapatkan bahwa data penelitian ini terdistribusi tidak normal maka uji statistik yang digunakan adalah uji statistik non parametrik wilcoxon. Hasil analisis selisih perubahan oral hygiene dari posttest ke pretest menunjukkan ada perubahan yang signifikan, ditunjukkan dengan $\mathrm{Z}=-3,126$ dan $\mathrm{p}=0,002(\mathrm{p}>0,05)$. Hal ini disebabkan karena pada dasarnya keadaan inteligensi anak tunanetra itu tidak berbeda dengan anak normal tetapi bermasalah dalam menerima informasi dan persepsi, oleh karena itu dibutuhkan pendekatan dan komunikasi yang baik dalam menanganinya sehingga lebih menarik perhatian responden dan mampu menstimulasi responden untuk meneruskan pesan yang diterima untuk di mengerti. Hal ini didukung oleh Notoatmodjo (2012) yang menyatakan bahwa media sebagai alat bantu menyampaikan pesan-pesan kesehatan, alat bantu tersebut mempunyai fungsi agar menimbulkan minat sasaran, mencapai sasaran yang lebih banyak, membantu dalam mengatasi banyak hambatan dalam pemahaman. Menstimulasi sasaran untuk meneruskan pesan-pesan yang diterima orang lain, mempermudah penyampaian bahan atau informasi kesehatan.

Selanjutnya dapat disimpulkan bahwa hipotesis yang menyatakan ada pengaruh Dental Braille Education (DBE) terhadap oral hygiene pada anak tunanetra dapat diterima.

\section{KESIMPULAN}

Dapat disimpulkan bahwa ada pengaruh Dental Braille Education (DBE) terhadap oral hygiene pada anak tunanetra karena pada dasarnya keadaan inteligensi anak tunanetra itu tidak berbeda dengan anak normal tetapi bermasalah dalam menerima informasi dan persepsi, oleh karena itu dibutuhkan pendekatan dan komunikasi yang baik dalam menanganinya sehingga lebih menarik perhatian responden dan mampu menstimulasi responden untuk meneruskan pesan yang diterima untuk dimengerti.

\section{DAFTAR PUSTAKA}

Agnintia, D., Rachmawati, F., Arsita, R. dan Berti, P.L., 2013. Quality Self Care And Home Care. Solusi Kesehatan Gigi Dan Mulut Anak Tunanetra Di SDLB A-Y Kab Surakarta. eProceeding TIMNAS. Ditjen Dikti Kemdikbud RI.

Broadbent, Jonathan M, Thomson, W.M., Boyens, J.V. dan Poulton, R., 2011. Dental Plaque and Oral Health during the First 32 Years of Life. Journal of the American Dental Association (1939) 142(4): 415-26. http://dx.doi.org/10.14219/jada.archiv e.2011.0197.

Maher,C.A., Lewis, L.K, Ferrar, K., Marshall, S., De Bourdeaudhuij, I., dan Vandelanotte, C., 2014. Are Health Behavior Change Interventions That Use Online Social Networks Effective? A Systematic Review. J Med Internet Res. 2014 Feb 14;16(2). 
Kadkhoda, Z, A Rezaei and Amiri. A, 2014. Efect of Visual Impairment Education on the Improvment of Oral Hygiene and Reduction of Periodontis Prevalence. International Journal of Medical Dentistry: 7-12.

Kementerian Kesehatan., 2010. Pedoman Pelayanan Kesehatan Anak di Sekolah Luar Biasa (SLB) Bagi Petugas Kesehatan. Direktorat Jenderal Bina Kesehatan Masyarakat, Jakarta.

Kementerian Pemberdayaan Perempuan dan Perlindungan Anak., 2013. Panduan Penanganan Anak Berkebutuhan Khusus Bagi Pendamping (Orang Tua, Keluarga dan Masyarakat). Deputi Bidang Perlindungan Anak Republik Indonesia, Jakarta.

Kumar, R V S Krishna, Nusrath Fareed and M Shanthi., 2013. The Effectiveness of Oral Health Education Program with and without Involving SelfMaintainable Oral Hygiene Skills among the Visually Impaired Children. International Journal of Scientific Study 01(03).

Neuman, W, Lawrence., 2006. Social Research Methods: Qualitative and Quantitative Approach. USA, University of Wisconsin, 227-234.

Notoatmodjo., 2012. Promosi Kesehatan dan Perilaku Kesehatan. Rineka Cipta, Jakarta.

Putri, M. H. dan Sirait, T., 2014. Pengaruh Pendidikan Penyikatan Gigi Dengan Menggunakan Model Rahang Dibandingkan Dengan Metode Pendampingan Terhadap Tingkat Comparison of Toothbrushing Education Effect to Dental and Oral Hygiene Levels between Jaw Model
Method and Mentoring Method on in. MKB Vol 46(40): 134-42.

Raiyani, C. M., R. Arora, Deepak P. Bhayya dan S. Dogra., 2014. Evaluation of Efficacy of Various Types of Toothbrush Grips Used to Remove Dental Plaque by Visually Impaired Children. Scholars Academic Journal of Biosciences 2(11): 742-45.

Ravishankar, P. L., 2013. Prevalence of Dental Caries and Oral Hygiene Status among School Going Children: An Epidemiological Study. Journal of Contemporary Dental Practice 14(4): 743-46.

Reddy, Venugopal K., 2014. A Comparison of Oral Hygiene Status and Dental Caries Experience among Institutionalized Visually Impaired and Hearing Impaired Children of Age between 7 and 17 Years in Central India. Journal of Indian Society of Pedodontics and Preventive Dentistry 31(3): 141-45.

Sheehy, N., 2004. Volume 59 Number 5 May 2004. American Foundation for the Blind. All rights reserved 59(5): 1-27.

Singh, Abhayjeet, Ashish Kumar, Vikas Berwal and Manjit Kaur., 2014. Original Article Comparative Study of Oral Hygiene Status in Blind and Deaf Children of Rajasthan. Depeartement of Oral Medicine and Radiology: 26-31.

Zeng, Xian-Tao, 2015. Meta-Analysis on the Association between Toothbrushing and Head and Neck Cancer. Oral Oncology 51(5): 446-51. http://linkinghub.elsevier.com/retriev e/pii/S1368837515001268. 